\title{
Indução, caracterização bioquímica e ultra-estrutural de calos de aroeira-do-sertão (Myracrodruon urundeuva Fr. All.)
}

\author{
VASCONCELOS, J.N.C. ${ }^{1}$; CARDOSO, N.S.N. ${ }^{1}$; OLIVEIRA, L.M. ${ }^{*}$; SANTANA, J.R.F. ${ }^{1}$; FERNANDEZ, L.G. ${ }^{2}$; BELLO \\ KOBLITZ, M.G. ; SILVA, M.L.C. \\ ${ }^{1}$ Unidade Experimental Horto Florestal, Departamento de Ciências Biológicas, Universidade Estadual de Feira de \\ Santana (UEFS), Avenida Presidente Dutra, Santa Mônica, CEP: 44.077-760, Feira de Santana-Brasil \\ *lenaldo@uefs.br Instituto de Ciências da Saúde (ICS), Universidade Federal da Bahia, Avenida Miguel Calmon, \\ s/n, CEP: 40140-100, Salvador-Brasil luzimargonzaga@gmail.com
}

\begin{abstract}
RESUMO: Aaroeira-do-sertão (Myracrodruon urundeuva Fr. All.) é espécie arbórea que apresenta grande valor econômico devido às propriedades químicas da casca com elevado teor de taninos. Em decorrência da exploração predatória encontra-se inserida na lista oficial de espécies da flora brasileira ameaçadas de extinção na categoria vulnerável. A micropropagação vem sendo colocada como importante forma de multiplicação dessa espécie, na busca de alternativa para a exploração sustentável. Este trabalho foi realizado com o objetivo de induzir calos a partir de segmentos foliares usando 2,4-D e caracterizá-los quanto aos aspectos morfológicos e bioquímicos. Os resultados obtidos indicam que é possível induzir calos a partir de segmentos foliares de aroeirado-sertão utilizando-se 2,4-diclorofenoxiacético (2,4-D). Os calos obtidos foram compactos e não-embriogênicos, apresentando valores médios de $43,32 \mathrm{mg} \mathrm{g}^{-1}$ de açúcares solúveis totais; $23,62 \mathrm{mg} \mathrm{g}^{-1}$ de açúcares redutores; $3,157 \mathrm{mg} \mathrm{g}^{-1}$ de proteína total; $3,147 \mathrm{mg} \mathrm{g}^{-1}$ de aminoácidos livres e $0,914 \mathrm{mg} \mathrm{g}^{-1}$ de compostos fenólicos totais na matéria fresca.
\end{abstract}

Palavras-chave: aroeira, calogênese, MEV, análises bioquímicas

\begin{abstract}
Induction, biochemical and ultrastructural characterization of the callus of "aroeira-do-sertão" (Myracrodruon urundeuva Fr. All.). "Aroeira-do-sertão" (Myracrodruon urundeuva Fr. All.) is a tree species that has great economic value due to the chemical properties of its bark, which has high tannin content. On account of the predatory exploitation it has been placed in the official list of threatened species of the Brazilian flora, in the vulnerable category. Micropropagation has been considered an important form of multiplication of this species in the search for an alternative for its sustainable exploitation. This study was conducted with the aim of inducing callus from leaf segments using 2,4-D and characterizing them according to their morphological and biochemical aspects. The obtained results indicate that it is possible to induce callus from leaf segments of $M$. urundeuva using 2,4-dichlorophenoxyacetic (2,4-D). The obtained calluses were compact and non-embryogenic, with average values of $43.32 \mathrm{mg} \mathrm{g}^{-1}$ total soluble sugars, $23.62 \mathrm{mg} \mathrm{g}^{-1}$ reducing sugars, $3.157 \mathrm{mg} \mathrm{g}^{-1}$ total protein, $3.147 \mathrm{mg} \mathrm{g}^{-1}$ free-form amino acids and $0.914 \mathrm{mg} \mathrm{g}^{-1}$ phenolic compounds in the fresh matter.
\end{abstract}

Key words: "aroeira", callus formation, SEM, biochemical analyses

\section{INTRODUÇÃO}

A aroeira-do-sertão (Myracrodruon urundeuva Fr. All.) é espécie arbórea pertencente à família Anacardiaceae que apresenta distribuição natural limitada a América do Sul, ocorrendo naturalmente desde o Ceará até a Argentina e Paraguai, sendo encontrada em formações vegetais de caatinga, cerrado e floresta pluvial (Lorenzi \& Matos, 2002). Essa espécie vem sendo muito explorada em função das propriedades químicas, biológicas e medicinais.
Em virtude da presença, na casca, de grandes quantidades de taninos, tem sido muito utilizada na indústria de curtimento de couros e medicina popular nordestina no tratamento de doenças dermatológicas, ginecológicas e como cicatrizante natural (Souza et al., 2007).

Entretanto, a exploração vem sendo feita de forma extrativista e desordenada, com forte impacto sobre as populações naturais. Na prática, retiram-se

Recebido para publicação em 20/08/2010

Aceito para publicação em 26/03/2012

Rev. Bras. PI. Med., Botucatu, v.14, n.4, p.592-597, 2012. 
da planta extensas áreas de tecido caulinar, independente da idade e do tamanho do vegetal, bem como da época do ano (Monteiro et al., 2005). Em decorrência dessa exploração predatória a preservação de populações dentro dos "habitats" naturais vem sendo comprometida. Como consequência, a aroeira-do-sertão foi inserida na lista oficial de espécies da flora brasileira ameaçadas de extinção na categoria vulnerável e recentemente foi incluída também na lista vermelha de espécies ameaçadas de extinção da IUCN (IBAMA, 1992; Moraes, 2006; Pacheco et al., 2006).

Diante do elevado potencial fitoquímico da aroeira-do-sertão é necessário que a prática de exploração adotada seja repensada, buscando-se o desenvolvimento de metodologias para exploração desses compostos a partir de plantas cultivadas. Nesse contexto, a biotecnologia vegetal tem sido considerada importante instrumento, por permitir tanto a propagação rápida quanto para obtenção de compostos bioativos de interesse via cultivo de células, órgãos e plantas in vitro.

Andrade et al. (2000), buscando estabelecer metodologia de micropropagação da aroeira-do-sertão, avaliaram o efeito de diferentes concentrações de fitorreguladores sobre o processo morfogenético de explantes oriundos de sementes germinadas in vitro. Esses autores verificaram ser possível a regeneração de plantas a partir de segmentos nodais e apicais, com posterior enraizamento e aclimatização das plantas, entretanto, os explantes apresentaram elevada taxa de oxidação e se desenvolveram em única brotação, o que reduz a taxa de multiplicação in vitro.

A organogênese indireta, passando pela fase de calo, tem sido a forma mais preconizada para a obtenção de elevadas taxas de multiplicação in vitro (Grattapaglia \& Machado, 1998). O calo é um aglomerado de células e tecidos formado pela intensa divisão das células do explante, sendo a friabilidade uma característica importante quando se objetiva a obtenção de embriões somáticos ou a produção de metabólitos secundários de interesse, via cultivo de células em suspensão (Barrueto Cid, 1992).

A caracterização morfológica, bioquímica e ultra-estrutural dos calos pode evidenciar as mudanças que ocorrem nas diferentes fases do crescimento do calo, fornecendo dados importantes relacionados ao processo morfogenético in vitro de tecidos vegetais. Esses estudos podem auxiliar ainda na identificação de fatores que desencadeiam mudanças fisiológicas nos explantes, como a aquisição da friabilidade ou desenvolvimento de embriões somáticos. Assim, esse trabalho teve como objetivo induzir a formação de calos em explantes foliares de aroeira-do-sertão e caracterizá-los quanto a aspectos morfológicos, bioquímicos e ultra-estruturais.

\section{MATERIAL E MÉTODO}

Os calos foram induzidos a partir de segmentos foliares obtidos de plantas estabelecidas in vitro, após 60 dias de cultivo, baseado na metodologia descrita por Andrade et al. (2000). Os segmentos foliares foram inoculados em meio de cultura WPM (Woody Plant Medium) (Lloyd \& McCown, 1980), suplementado com 3\% de sacarose e cinco diferentes concentrações de 2,4diclorofenoxiacético (2,4-D) $(2,26 ; 4,52 ; 6,78 ; 9,04$; $18,09 \mu \mathrm{M})$. O meio de cultura foi solidificado com $0,7 \%$ de ágar e o $\mathrm{pH}$ foi corrigido para 5,7 $\pm 0,1$ antes da autoclavagem. Após a inoculação as culturas permaneceram no escuro até o final do experimento, sendo mantidas em sala de crescimento com temperatura de $25^{\circ} \mathrm{C} \pm 2^{\circ} \mathrm{C}$. Para cada tratamento foram utilizadas dez repetições, com cinco tubos por parcela e um explante por tubo, em delineamento estatístico inteiramente casualizado. Após 45 dias de cultivo avaliou-se a porcentagem de calos formados, porcentagem de calos oxidados, coloração e consistência dos calos. Tipos morfológicos de calos encontrados em maior quantidade foram coletados para análise bioquímica e ultra-estrutural via microscopia eletrônica de varredura (MEV).

Para obtenção da curva de crescimento, explantes foliares foram inoculados em meio WPM suplementados com $3 \%$ de sacarose, $0,7 \%$ de ágar e 4,52 $\mu \mathrm{M}$ de 2,4-D, nas mesmas condições ambientais descritas anteriormente. Foi quantificado o peso seco dos calos a partir do dia da inoculação (tempo 0) até o 70 dia, com intervalos de coleta de sete dias, utilizando-se 10 repetições por período de coleta, com cada repetição constituída por um tubo com um explante. O percentual de crescimento dos calos foi determinado a partir da equação:

$$
\mathrm{Pf}-\mathrm{Pi} / \mathrm{Pf} \times 100
$$

onde: $\mathrm{Pi}=$ peso inicial e $\mathrm{Pf}=$ peso final de calos.

Para análise bioquímica foi obtido extrato aquoso conforme metodologia descrita por Nogueira et al. (2008). Os calos foram homogeneizados em graal e para cada grama de calo foram adicionados 4 $\mathrm{mL}$ de água destilada. As amostras permaneceram a $40^{\circ} \mathrm{C}$ em banho-maria por 30 minutos e foram centrifugadas a $4800 \times$ g por 30 minutos a $25^{\circ} \mathrm{C}$. $\mathrm{O}$ sobrenadante foi recolhido e armazenado sob refrigeração para posterior análise. A quantificação dos açúcares solúveis totais (AST) foi realizada por refratometria; dos açucares redutores (AR) pelo método do DNS (Miller, 1959); da proteína bruta (PB) e aminoácidos livres (AA) pelo método descrito por Lowry et al. (1951) e dos fenóis totais pelo método de Folin-Ciocalteau (1927), utilizando-se curva padrão de acido gálico. Para obtenção dos aminoácidos totais livres foi realizada a precipitação das proteínas com o ácido tricloacético a $25 \%$, deixando apenas os aminoácidos livres e pequenos peptídeos em solução. 
Para todas as análises bioquímicas foram utilizadas três repetições em cada tratamento, com 20 tubos por repetição, avaliando-se estatisticamente os resultados mediante a análise de variância e comparando-se as médias pelo teste de Tukey a $5 \%$ de probabilidade.

Para a análise ultra-estrutural os calos foram imersos em solução fixadora de glutaraldeído e desidratados em concentrações crescentes de acetona (30, 70, 80, 90, 95 e 100\%), por 5 minutos em cada concentração, repetindo-se o processo por três vezes. Após a desidratação as amostras foram levadas para o aparelho de ponto crítico (CPD 030) para a secagem durante 30 minutos e, então, montadas em stubs para metalização com ouro no metalizador SCD 050 durante 60 minutos. Finalmente, a observação das amostras foi realizada em Microscópio Eletrônico de Varredura LEO 1430 VP Carl Zeiss do Brasil.

\section{RESULTADO E DISCUSSÃO}

O percentual de calos obtidos variou significativamente em função das diferentes concentrações da auxina utilizada, obtendo-se maior porcentagem de formação de calos nas concentrações 4,52 e 6,78 $\mu \mathrm{M}$ de 2,4-D (Tabela 1). A menor taxa de oxidação dos calos foi obtida em meio de cultura suplementado com as menores concentrações de 2,4-D (Tabela 1). Bonilla (2002) também obteve maior taxa de indução de calo em explante foliar de chá-de-bugre (Rudgea viburnoides) utilizando 4,52 $\mu \mathrm{M}$ de 2,4-D em condição de ausência de luz. De modo semelhante, Nogueira et al. (2007a) observaram que a concentração de $4,52 \mu \mathrm{M}$ de 2,4-D promoveu a maior percentagem de área coberta por calos (90\%) em murici-pequeno (Byrsonimia intermedia).

O padrão típico de crescimento de calos obtidos nesse trabalho foi sigmoidal com tendência de ganho de matéria seca até o 56으 dia após a inoculação, caracterizando o início da fase de desaceleração (Figura 1). Segundo Azevedo (2003), a identificação dessa fase é importante, pois indica o momento que se deve transferir os calos para novo meio de cultura devido à redução de nutrientes e acúmulo de substâncias tóxicas. Landa (2000) verificou que para calos obtidos de segmentos foliares de pequizeiro, a transferência para novo meio de cultura deve ocorrer entre o 46ㅇ e o 49ㅇ dia de cultivo. Já Santos et al. (2008) verificaram que a repicagem de calos provenientes de folhas de Coffea canephora deve ser efetuada aos 70 dia de cultivo.

Os calos formados a partir de segmentos foliares de aroeira-do-sertão apresentaram variações na coloração, consistência e morfogênese. Entretanto, os tipos morfológicos que predominaram, independentemente da concentração de 2,4-D foram os calos marrons, compactos e indiferenciados (Figura 2).

Para a obtenção de culturas embriogênicas é indispensável à indução de calos friáveis, por conter células arredondadas e com características meristemáticas. Segundo Pescador et al. (2000), a friabilidade do calo é favorecida pela alta relação auxina/citocinina, bem como pela adição de componentes orgânicos ao meio nutritivo. Contudo, em nenhum dos tratamentos com adição da auxina 2,4-D testadas nesse trabalho obteve-se calos completamente friáveis. A análise da superfície dos calos de aroeira-do-sertão através da microscopia eletrônica de varredura (MEV) demonstrou a ocorrência de estruturas não granulares e compactas em alguns setores do calo (Figura 3A). Próximo a esses setores compactos verificou-se a ocorrência de células foliares e arranjadas frouxamente na superfície (Figura 3B), intercaladas por algumas células pequenas e esféricas, sugerindo o início da proliferação de células embriogênicas. Ainda nesses setores compactos foi possível à identificação, de forma dispersa, de pequenas protuberâncias na superfície do calo (Figura 3C), com uma abertura na extremidade, semelhante a um coleóptilo, o que possivelmente representa a fase inicial da

TABELA 1. Porcentagem de calos formados e oxidados obtidos a partir de explantes foliares de Myracrodruon urundeuva Fr. All. cultivados em meio WPM suplementado com diferentes concentrações de 2,4-D.

\begin{tabular}{ccc}
\hline $\begin{array}{c}\text { Concentração de 2,4-D } \\
(\mu \mathrm{M})\end{array}$ & $\begin{array}{c}\text { Formação de calos } \\
(\%)\end{array}$ & $\begin{array}{c}\text { Oxidação } \\
(\%)\end{array}$ \\
\hline 2,26 & $45,00 \mathrm{c}$ & $30,00 \mathrm{a}$ \\
4,52 & $87,50 \mathrm{a}$ & $35,00 \mathrm{a}$ \\
6,78 & $82,50 \mathrm{ab}$ & $52,50 \mathrm{ab}$ \\
9,04 & $55,00 \mathrm{bc}$ & $75,00 \mathrm{~b}$ \\
18,09 & $30,00 \mathrm{c}$ & $80,00 \mathrm{~b}$ \\
\hline $\mathrm{CV}(\%)$ & 20,81 & 26,07 \\
\hline
\end{tabular}

*Médias seguidas de mesma letra na coluna não diferem entre si significativamente ao nível de $5 \%$ de probabilidade pelo teste de Tukey.

Rev. Bras. PI. Med., Botucatu, v.14, n.4, p.592-597, 2012. 


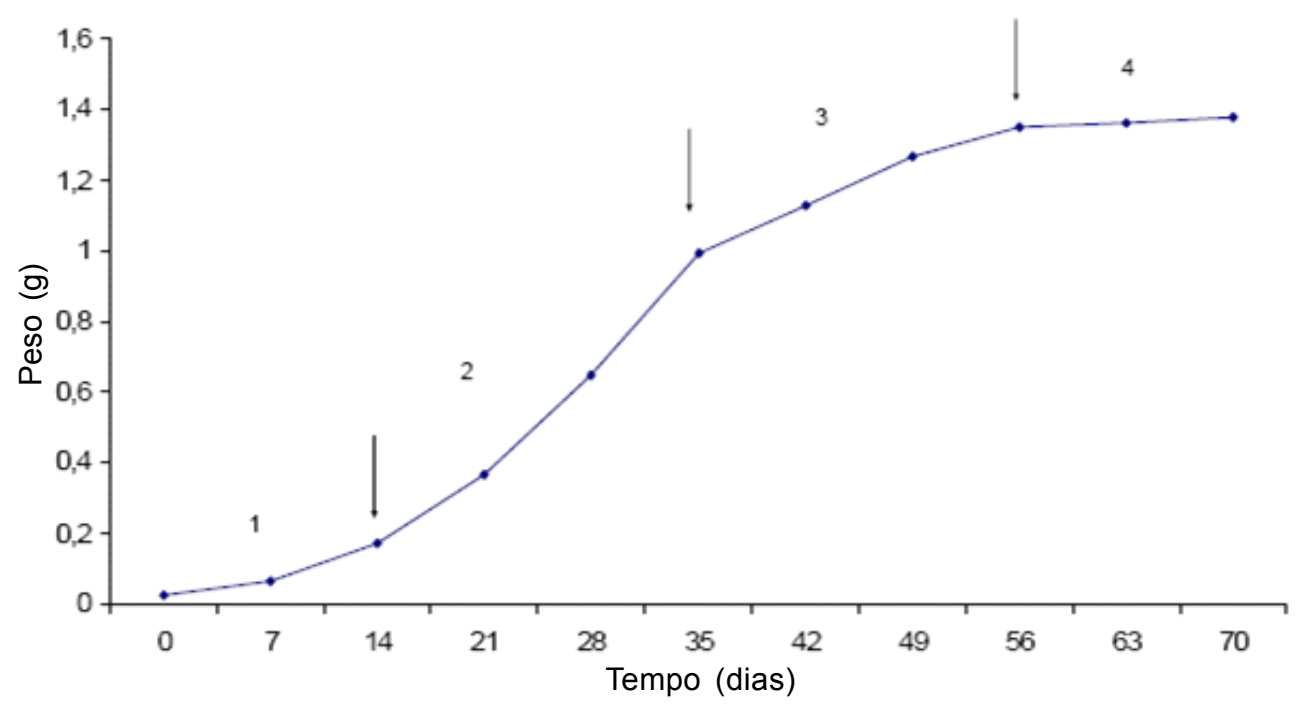

FIGURA 1. Curva de crescimento de calos de aroeira-do-sertão (Myracrodruon urundeuva Fr. All.) obtidos a partir de segmentos foliares inoculados em meio WPM suplementado com 4,52 $\mu \mathrm{M}$ de 2,4-D, durante 70 dias. 1. Fase lag; 2. Fase exponencial; 3. Fase linear; 4. Fase de desaceleração.

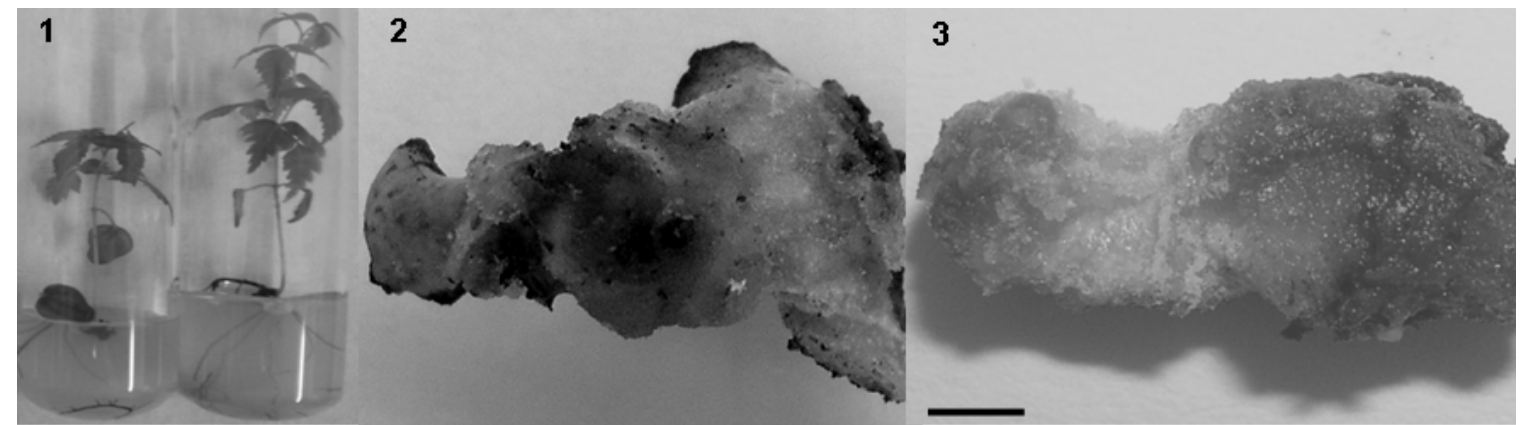

FIGURA 2. Estágios da formação dos calos de Myracrodruon urundeuva Fr. All. cultivado em meio WPM. 1. Planta de aroeira estabelecida in vitro com 60 dias de idade usada como fonte de explantes; 2 . Início da formação dos calos; 3. Tipo morfológico de calo encontrado em maior quantidade. Barra equivale a 0,5 mm.

embriogênese somática, entretanto, não foram evidenciados embriões somáticos típicos. Verificouse ainda pela análise com MEV a ocorrência de outros setores distintos do primeiro, com aspecto mais granular, embora não totalmente friável e constituídos de células com formato alongado (Figuras 3D, 3E e $3 F$ ), característico de estruturas não embriogênicas (Nogueira et al., 2007b).

Para Nogueira et al. (2007b), o formato isodiamétrico é característico de células meristemáticas e os calos embriogênicos são compostos, na maioria, por células meristemáticas com dimensões relativamente pequenas e com citoplasma denso. De modo semelhante, Williams \& Maheswaran (1986) apontam como características de calos embriogênicos a presença de células com pequena dimensão, conteúdo citoplasmático denso, com grandes núcleos proeminentes, nucléolos alargados, vacúolos pequenos e profusão de grãos de amido e proteínas totais. Para esses autores os embriões somáticos derivados de células apresentando essas características, originam-se a de setores de calos friáveis.

A análise bioquímica dos calos de aroeirado-sertão revelou teor de 3,157 $\mathrm{mg} \mathrm{g}^{-1} \mathrm{MF}$ de proteína total e 3,147 $\mathrm{mg} \mathrm{g}^{-1} \mathrm{MF}$ de aminoácidos livres. O teor de proteínas encontrado nesse trabalho foi maior que o observado por Santos etal. (2008) em calos de Coffea canephora e por Santos et al. (2003) em calos de Coffea arábica. Entretanto, foi menor que o valor observado por Azevedo (2003) em calos de copaíba (Copaifera langsdorffii) (4,54 mg g-1 MF). Para Santos et al. (2008), as proteínas constituem a maior parte da matéria seca da célula e as variações qualitativas e quantitativas representam o conjunto específico de atividades bioquímicas e celulares, típico de cada fase de desenvolvimento do calo. O maior teor de proteínas observado nos calos de aroeira-do-sertão pode ser atribuído à época de coleta dos calos (45 dias de cultivo), correspondente à fase linear de crescimento dos calos 

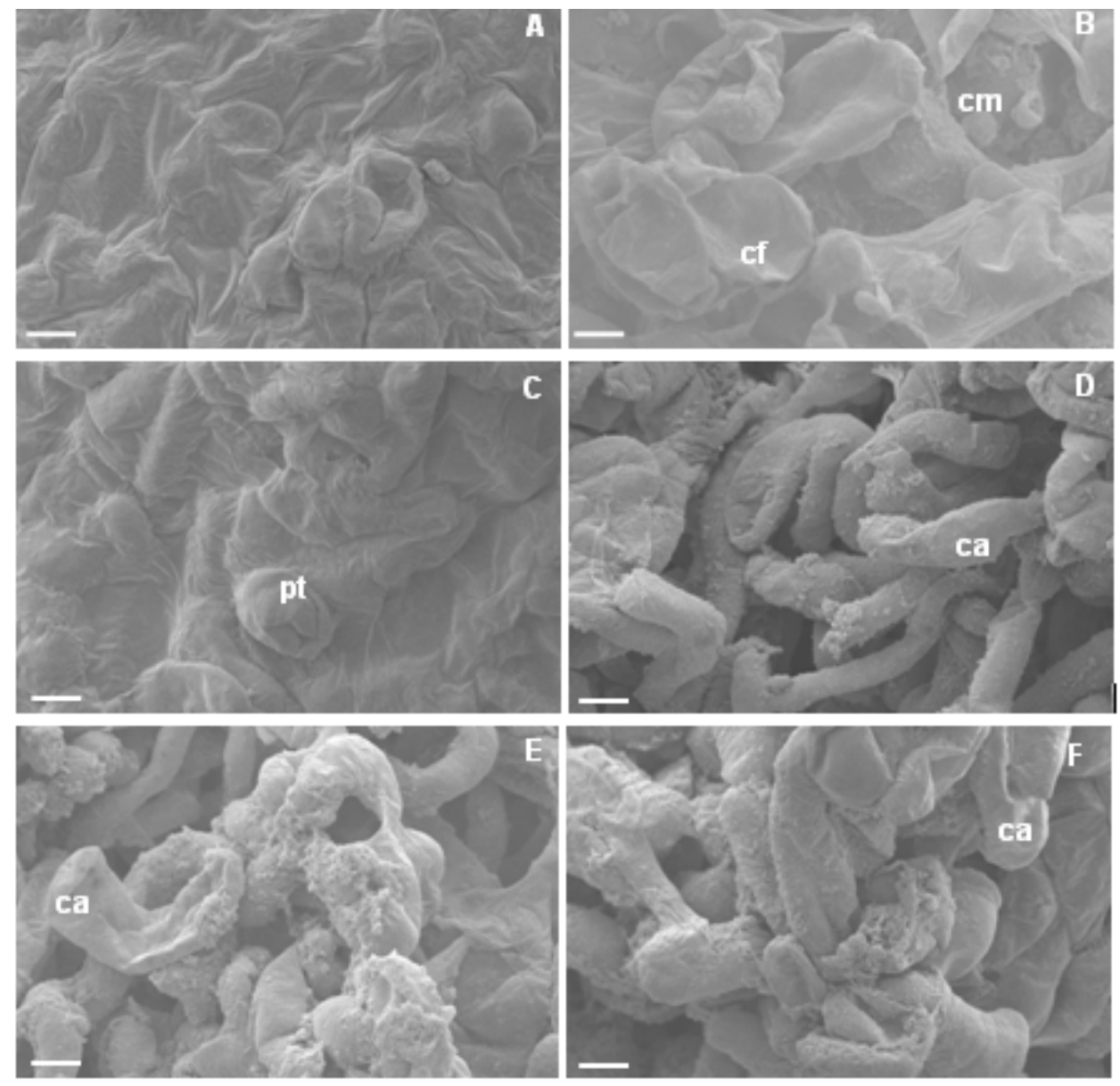

FIGURA 3. Eletromicrografia de varredura dos calos obtidos a partir de segmentos foliares de aroeira-do-sertão (Myracrodruon urundeuva Fr. All.). A e C - Massa compacta de células; B - Estrutura granular na superfície do calo, sugerindo o início da proliferação de células embriogênicas; D, E e F - Células alongadas e não embriogênicas formadas na superfície dos calos. (cm) células meristemáticas, (pt) protuberância semelhante a um coleóptilo, (cf) células foliares, (ca) células alongadas. As barras equivalem a $20 \mu \mathrm{m}$.

(Figura 1), pois este parâmetro tem sido utilizado como marcador bioquímico de crescimento celular.

O teor de açúcar solúvel total foi equivalente a 43,32 $\mathrm{mg} \mathrm{g}^{-1} \mathrm{MF}$. Esse valor é muito superior ao obtido por Nogueira et al. (2008) em calos de muricipequeno (Byrsonimia intermedia A. Juss.) $(0,03 \mathrm{mg}$ $\left.\mathrm{g}^{-1} \mathrm{MF}\right)$. Os teores de açúcares em calos são muito variáveis, havendo tendência geral de declínio, com o teor máximo sendo verificado, geralmente, no dia da inoculação dos explantes (Serra et al., 2000). Para os açúcares redutores, verificou-se em calos de aroeira-do-sertão a concentração de $23,62 \mathrm{mg} \mathrm{g}^{-1} \mathrm{MF}$, valor superior ao obtido para calos de Copaifera langsdorffii (14,57 $\mathrm{mg} \mathrm{g}^{-1} \mathrm{MF}$ ) (Azevedo, 2003).

Em relação aos teores de compostos fenólicos totais, verificou-se nesse trabalho a concentração média de $0,914 \mathrm{mg} \mathrm{g}^{-1} \mathrm{MF}$, equivalendo a aproximadamente $0,9 \%$ da massa fresca do calo, obtido em fase linear da curva de crescimento. Esses valores são relativamente mais elevados que os obtidos por Nogueira et al. (2008), em trabalho com murici-pequeno (Byrsonimia intermedia A. Juss.), verificaram teores de taninos equivalentes a $0,142 \mathrm{e}$ $0,133 \%$ da matéria fresca de calos, nas fases linear e estacionária da curva de crescimento dos calos, respectivamente. Contudo, ressalta-se que a metodologia utilizada nesse trabalho proporcionou a extração de uma maior gama de compostos fenólicos em relação à utilizada por Nogueira et al. (2008). Por outro lado, os valores de fenóis totais obtidos nos calos são relativamente baixos em relação aos obtidos na casca da aroeira-do-sertão, tecido onde se verifica a maior concentração de taninos, sendo, por isso, a parte do vegetal mais utilizada comercialmente $(9,28 \%$ e $8,18 \%$ de fenóis totais e taninos, respectivamente) (Monteiro et al., 2005).

Os compostos fenólicos representam um grupo químico de grande interesse para a espécie aroeira-do-sertão, tanto sob o aspecto fitoquímico quanto industrial. Em ambiente natural esses 
compostos são encontrados principalmente nos vacúolos das plantas. Assim, a baixa concentração de compostos fenólicos totais nos calos de Myracrodruon urundeuva pode estar relacionada ao tamanho reduzido das células, indicando o baixo grau de diferenciação dos calos obtidos. Entretanto, sugerem a possibilidade de produção desses compostos via cultura de células.

\section{CONCLUSÃO}

É possível a indução de calos em segmentos foliares de aroeira-do-sertão utilizando 2,4-D, com maior taxa de calogênese obtida na concentração de $4,52 \mu \mathrm{M}$ desse regulador vegetal. Os calos obtidos a partir de segmentos foliares com a utilização dessa auxina apresentaram textura compacta e características não-embriogênicas. A presença de fenólicos totais nos calos de aroeira-do-sertão sugere a necessidade de realização de trabalhos futuros visando à identificação dos compostos presentes. Sugere ainda a possibilidade de exploração desses compostos usando abordagens biotecnológicas, para produção de substâncias bioativas in vitro.

\section{REFERÊNCIA}

ANDRADE, M.W. et al. Micropropagação da aroeira (Myracrodruon urundeuva Fr. All.). Ciência e agrotecnologia, v.24, n.1, p.74-180, 2000.

AZEVEDO, K.S. Indução e análises bioquímicas de calos e aspectos de anatomia foliar de Copaíba (Copaifera langsdorffii Desf.). 2003. 86p. Dissertação (Mestrado - Área de concentração em Agronomia/ Fitotecnia) - Departamento de Agricultura, Universidade Federal de Lavras, Lavras.

BARRUETO CID, L.P.B. A cultura de células vegetais em meio líquido. ABCTP Notícias, n.18, p.2-7, 1992.

BONILLA, M.G.O. Propagação in vitro, indução, curva de crescimento de calos e abordagem fitoquímica em Rudgea viburnoides (Cham.) Benth. 2002. 162p. Tese (Doutorado - Área de concentração em Agronomia/ Fitotecnia) - Departamento de Agricultura, Universidade Federal de Lavras, Lavras.

FOLIN, O.; CIOCALTEAU, V. On tyrosine and tryptophane determination in proteins. Journal of Biology and Chemistry, v.73, p.627-50, 1927.

GRATTAPAGLIA, D.; MACHADO, M.A. Micropropagação. In: TORRES, A.C.; CALDAS, L.S.; BUSO, J.A. Cultura de tecidos e transformação genética de plantas. v.1. Brasília: Embrapa-SPI /Embrapa CNPH, 1998. p.183260.

IBAMA. Instituto Brasileiro do Meio Ambiente e dos Recursos Naturais Renováveis. Lista oficial das espécies da flora ameaçadas de extinção. Diário Oficial. Portaria 006/92-N de 15 de janeiro de 1992. Disponível em: <http:/www.ibama.gov.br/flora/extincao.htm>. Acesso em: 23 jul. 2006

LANDA, F.S.L. et al. Indução in vitro de calos em explantes foliares de pequizeiro (Caryocar brasiliense Camb.). Ciência e agrotecnologia, v.24, p.56-63, 2000. LLOYD, G.; McCOWN, B. Use of microculture for production and improvement of Rhododendron spp. HortScience, v.15, p.416-21, 1980.

LORENZI, H.; MATOS, F.J.A. Plantas medicinais no Brasil: nativas e exóticas cultivadas. Nova Odessa: Plantarum, 2002. 512p.

LOWRY, O.H.; ROSEBROUGH, N.J.; FARR, A.L. Protein measurement with the Folin phenol reagent. Journal of Biological Chemistry, v.193, p.265-75, 1951.

MILLER, G.L. Use of dinitrosalicylic acid reagent for determination of reducing sugar. Analysis Chemical, v.31, p.426-28, 1959.

MONTEIRO, J.M. et al. Teor de taninos em três espécies medicinais arbóreas simpátricas da caatinga. Revista Árvore, v.29, n.6, p.999-1005, 2005.

MORAES, J.P.S. Estudos sobre a propagação in vitro da aroeira (Myracrodruon urundeuva Fr. Allemão). 2006. 116p. Dissertação (Mestrado - Área de concentração em Bioquímica) - Universidade Federal do Ceará, Fortaleza.

NOGUEIRA, R.C. et al. Indução de calos em explantes foliares muricipequeno (Byrsonima intermedia A. Juss.). Ciência e agrotecnologia, v.31, n.2, p.366-70, 2007a.

NOGUEIRA, R.C. et al. Análise ultra-estrutural de calos embriogênicos de murici-pequeno (Byrsonima intermedia A. Juss.). Revista Brasileira de Biociências, v.5, supl.2, p.48-50, 2007b.

NOGUEIRA, R.C. et al. Curva de crescimento e análises bioquímicas de calos de murici-pequeno (Byrsonima intermedia A. Juss.). Revista Brasileira de Plantas Medicinais, v.10, n.1, p.44-8, 2008.

PACHECO, M.V. et al. Efeito de temperaturas e substratos na germinação de sementes de Myracrodruon urundeuva Fr. All. (ANACARDIACEAE). Revista Árvore, v.30, n.3, p.359-67, 2006.

PESCADOR, R. et al. Biotecnologia da Piper hispidinervium - Pimenta longa. Biotecnologia Ciência e Desenvolvimento, v.15, p.18-23, 2000.

SANTOS, C.G. et al. Indução e análise bioquímica de calos obtidos de segmentos foliares de Coffea arabica L., cv. Rubi. Ciência e agrotecnologia, v.27, n.3, p.571-7, 2003. SANTOS, C.G. et al. Indução e análise bioquímica de calos em segmentos foliares e nodais de Coffea canephora L. cv. APOATÃ. Magistra, v.20, n.1, p.22-9, 2008.

SERRA, A.G.P.; PAIVA, R.; PAIVA, P.D.O. Análises bioquímicas de calos formados de explantes foliares de Castanha-do-Brasil (Bertholletia excelsa H.B.K.). Ciência e agrotecnologia, v.24, n.4, p.833-40, 2000.

SOUZA, S.M.C. et al. Antiinflammatory and antiulcer properties of tannins from Myracrodruon urundeuva Allemão (Anacardiaceae) in Rodents. Phytotherapy Research, v.21, p.220-5, 2007.

WILLIAMS, E.G.; MAHESWARAN, G. Somatic embryogenesis: factors influencing coordinated behavior of cells as an embryogenic group. Annals of Botany, v.57, n.3, p.443-62, 1986. 